\title{
Effect of sodium ascorbate on bond strength and metalloproteinases activity in bleached dentin
}

This article was published in the following Dove Press journal:

Clinical, Cosmetic and Investigational Dentistry

\author{
Gláucia Cristina Rodrigues \\ Nascimento' \\ Mara Eliane Soares Ribeiro' \\ Marcella Yasmin Reis \\ Guerreiro' \\ Eduardo Luís de Souza $\mathrm{Cruz}^{2}$ \\ João de Jesus Viana Pinheiro \\ Sandro Cordeiro Loretto' \\ 'Dental Materials Laboratory of the \\ Postgraduate Program in Dentistry, \\ Institute of Health Sciences, School of \\ Dental, Federal University of Pará, Belém, \\ Pará, Brazil; ${ }^{2}$ Department of Oral \\ Pathology, School of Dental, Federal \\ University of Pará, Belém, Pará, Brazil
}

Correspondence: Sandro Cordeiro Loretto

Dental Materials Laboratory of the Postgraduate Program in Dentistry, Institute of Health Sciences, School of Dental, Federal University of Pará, Avenue Conselheiro Furtado, Number 2312, Tower Oásis, Ap. 401, Cremação, Belém, Pará 66.040-100, Brazil

Tel +559198 1223477

Email sandroloretto@hotmail.com

\begin{abstract}
Aim: This study evaluated the effect of sodium ascorbate (SA) on the proteolytic activity of matrix metalloproteinases (MMPs) and investigated the related effects on the bond strength of bleached dentin.

Materials and methods: Eighty freshly extracted human third molars were randomly divided according to treatment (bleaching or SA application), type of analysis (microshear or measuring MMP activity), and post-bleaching time to assess bond strength ( $24 \mathrm{hrs}$ or 30 days). Data from both analyses were subjected to one-way analysis of variance to detect differences among groups, followed by Tukey's multiple comparison test $(p \leq 0.05)$.

Results: Dental bleaching significantly reduced bond strength values when the adhesive strategy was performed after $24 \mathrm{hrs}$ (despite the SA treatment) or 30 days after the bleaching procedure. However, after 30 days, the bond strength values of the groups who received bleaching or SA application were similar to those of the unbleached group. Dental bleaching caused the activation of MMPs, and SA did not influence this activity.
\end{abstract}

Conclusion: It was concluded that SA does not affect the activity of MMPs or the bond strength in bleached dentin immediately after the bleaching treatment.

Keywords: tooth bleaching, antioxidants, bleaching agents, dental bonding

\section{Introduction}

Bleaching agents can cause morphological and/or chemical changes in enamel and dentin, ${ }^{1}$ interfere on penetration, and even inhibit complete polymerization of the applied adhesive systems and the formation of resinous tags, harming the hybridization of the bleached substrates. ${ }^{2}$

For the bond strength to be restored, it has been proposed that the restorative treatment be delayed for $24 \mathrm{hrs}$ to 28 days after bleaching to allow complete release of the residual oxygen present in the tooth structure. ${ }^{2}$ However, as an alternative to reduce this wait time, several studies have used sodium ascorbate (SA) as a neutralizing agent for the oxidizing effects generated by bleaching gels. ${ }^{3-5}$ The effect of SA on the bond strength of bleached dentin has been widely evaluated in mechanical assays, although the SA reaction, as well as possible changes that it may cause to the dental structure, are still poorly understood. ${ }^{3-6}$

However, in addition to the adequate diffusion of resinous monomers in the dentin substrate, the longevity of the hybrid layer also depends on the quality of the collagen fibril mesh. ${ }^{6}$ The loss of collagen has been suggested to contribute to the diminished mechanical properties of dentin. ${ }^{7}$ In this sense, recent evidence has shown that the reactive oxygen species generated by the bleaching gels are capable of activating the matrix metalloproteinases (MMPs) present in the dentin. ${ }^{8}$ MMPs are proteases 
secreted by odontoblasts during dentinogenesis, remaining inactive within the extracellular matrix. ${ }^{9}$ However, under certain conditions, such as at acidic $\mathrm{pH}$, these proteases are activated, causing collagen degradation. ${ }^{10}$ This feature is responsible for the relevant role of MMPs in compromising the resin/dentin interface. ${ }^{11}$

In addition, SA is believed to protect biological dental structures from damage caused by the toxic components resulting from bleaching. ${ }^{12}$ Such components may stimulate odontoblasts, fibroblasts, or other pulp cells to secrete more MMPs. ${ }^{13}$ In this context, considering that SA reduces the amount of reactive oxygen species present in the dental structure, thus, it may inhibit or even significantly reduce the action of MMPs on bleached dentin.

Thus, the objective of this study was to verify the possible effect of SA on the enzymatic activity of MMPs, correlating these findings with the adhesive bond strength of bleached dentin. The null hypothesis to be tested is that SA has no effect on collagenolytic activity of MMPs and bond strength of bleached dentin.

\section{Materials and methods}

\section{Specimen selection}

After approval by the Research Ethics Committee for Humans Beings of University Federal of Pará (protocol number- 31,224,214.8.0000.0018), 80 human third molars were included, from patients aged $18-30$ years, in agreement with the informed consent form signed by the donors.

The teeth were immersed for 1 week in $0.1 \%$ thymol solution (Fórmula, Belém, PA, Brazil) for disinfection, followed by the removal of adhered periodontal tissue and prophylaxis with pumice paste. Next, the teeth were stored in distilled water $\left(4^{\circ} \mathrm{C}\right)$, which was changed weekly until the start of the experiment. ${ }^{14}$

\section{Sample preparation}

For the microshear test, 60 teeth were cut horizontally at the occlusal third of the crown using a double-sided diamond disk (Microdont, São Paulo, SP, Brazil), under cooling with distilled water, to remove superficial enamel and dentin. Next, the dentin surface was flattened using silicon carbide sandpaper (3M, Sumaré, SP, Brazil) of decreasing grit (180, 400, and 600), under water cooling, in a horizontal polisher (Aropol-E - Arotec, Cotia, SP, Brazil). Tooth remnants were embedded in PVC matrices with chemically activated acrylic resin (JET, Clássico, Campo Limpo Paulista, SP,
Brazil). Immediately afterwards, the specimens were randomly divided into five groups $(\mathrm{n}=12)$ according to the treatment (Table 1) and stored in distilled water at $37^{\circ} \mathrm{C} .{ }^{15}$

To measure MMP activity, the superficial enamel and dentin of 20 teeth were removed using a double-sided diamond disc (Microdont, São Paulo, SP, Brazil) under water cooling. Then, a 1-mm-thick dentin disc was obtained from the middle coronal region of each tooth using a precision cutter (ISOMET low-speed saw, Buehler Ltd., Lake Bluff, IL, USA) under water cooling. Afterwards, 30 rectangular dentin fragments $\left(2 \times 1 \times 6 \mathrm{~mm}^{3}\right)$ were obtained with the aid of a digital calliper from the dentin discs and randomly divided into six groups $(\mathrm{n}=5)$ according to the treatment to which they were subjected (Table 2). ${ }^{16}$

The trade name, manufacturer, composition, and method of application of the materials used in the respective treatments are detailed in Table 3.

\section{Dental bleaching}

Tooth bleaching was performed according to the manufacturer's instructions (Table 3). Specimens used for the

Table I The mean (standard deviation) microshear bond strength (MPa) for each treatment and storage time by group

\begin{tabular}{|l|l|l|l|}
\hline Groups & Dental bleaching & Storage time & Mean (SD) \\
\hline GI & Untreated (control) & 24 hrs & $17.68(4.87)$ a \\
G2 & $38 \%$ HP & 24 hrs & $12.04(3.75)$ b \\
G3 & $38 \%$ HP & 30 days & $11.82(3.54)$ b \\
G4 & $38 \% \mathrm{HP}+10 \%$ SA & 24 hrs & $12.33(5.88)$ b \\
G5 & $38 \%$ HP $+10 \%$ SA & 30 days & $16.60(5.64)$ a \\
\hline
\end{tabular}

Note: Different letters indicate a significant difference using one-way ANOVA and Tukey's test for multiple comparisons ( $p \leq 0.05$ ).

Abbreviations: HP, hydrogen peroxide; SA, sodium ascorbate.

Table 2 Mean (standard deviation) total matrix metalloproteinase (MMP) activity (absorbance) present in dentin (ng/fragment) for each treatment by group

\begin{tabular}{|l|l|l|}
\hline Groups & Dental treatments & $\begin{array}{l}\text { Absorbance mean } \\
\text { (standard deviation) }\end{array}$ \\
\hline GI & Positive control (rh MMP-9) & $0.084(0.002) \mathrm{a}$ \\
G2 & $37 \%$ PA & $0.104(0.006) \mathrm{b}$ \\
G3 & $37 \%$ PA + Single Bond & $0.093(0.010) \mathrm{ab}$ \\
& Universal & \\
G4 & $38 \% \mathrm{HP}$ & $0.083(0.004) \mathrm{a}$ \\
G5 & $38 \% \mathrm{HP}+10 \% \mathrm{SA}$ & $0.080(0.005) \mathrm{a}$ \\
G6 & $38 \% \mathrm{HP}+10 \% \mathrm{SA}+37 \% \mathrm{PA}$ & $0.091(0.006) \mathrm{a}$ \\
\hline
\end{tabular}

Note: Different letters indicate a significant difference using one-way ANOVA and Tukey's test for multiple comparisons ( $p \leq 0.05)$.

Abbreviations: PA, phosphoric acid; HP, hydrogen peroxide; SA, sodium ascorbate. 


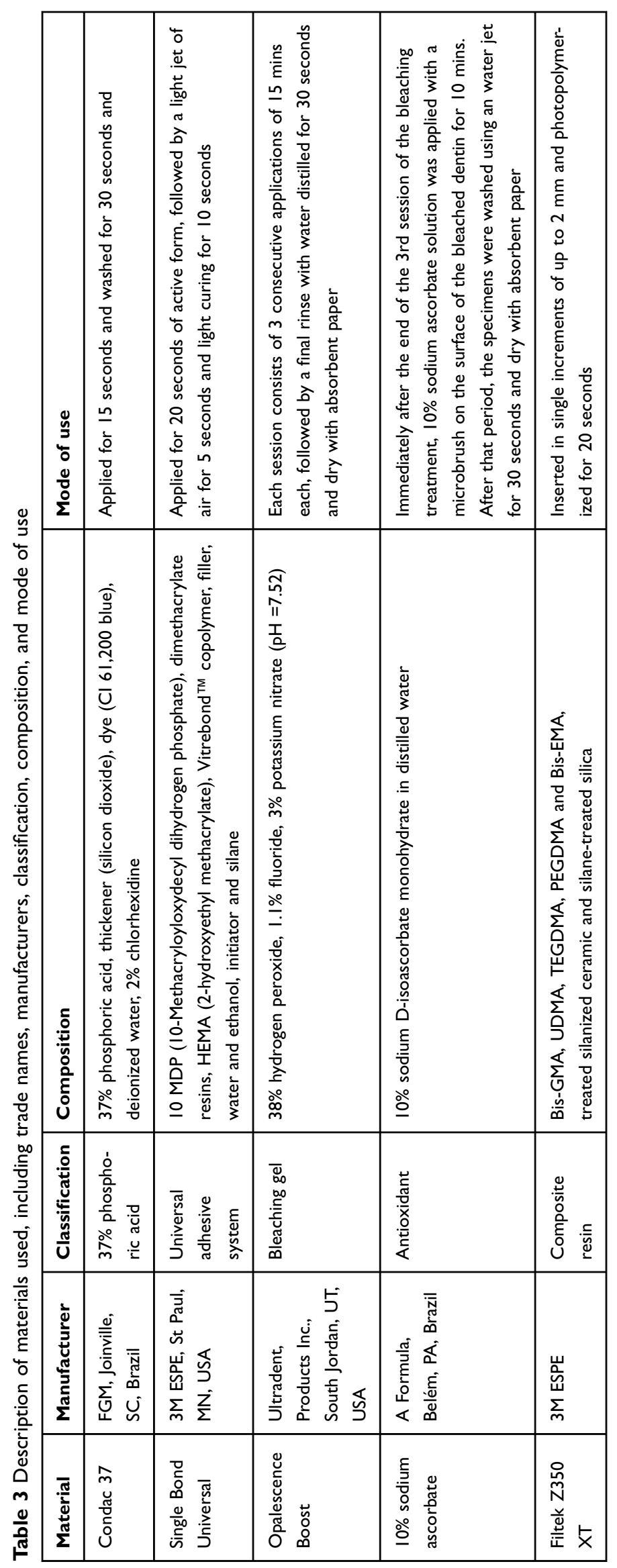


microshear test were subjected to three bleaching sessions, with a 3-day interval between them. Between sessions, the specimens were stored in distilled water $\left(37^{\circ} \mathrm{C}\right)$. For the evaluation of MMP activity, the specimens received only one bleaching session. In groups subjected to the use of $10 \% \mathrm{SA}$, it was applied immediately after the last dental bleaching session.

\section{Microshear test}

Two post-bleaching treatment wait times ( $24 \mathrm{hrs}$ and 30 days) were adopted to perform the adhesive bonding, with the specimens remaining stored in distilled water $\left(37^{\circ} \mathrm{C}\right)$ during this period, with daily renewal. After the wait times, an acidresistant double-sided adhesive tape was applied to the dentin surface of the specimens (Tectape, Manaus, AM, Brazil), which was perforated in a circular shape $(0.8 \mathrm{~mm}$ in diameter). Next, acid-conditioning dentin (Condac 37, FGM, Joinville, SC, Brazil), application of the adhesive system (Single Bond Universal, 3M ESPE, St Paul, MN, USA), and light curing (Ultrablue D-2000, DMC, São Carlos, SP, Brazil) with a light intensity of $900 \mathrm{~mW} / \mathrm{cm}^{2}$ for 10 seconds were performed. The first layer of tape was removed, and Tygon $^{\circledR}$ tubes $(0.8 \mathrm{~mm}$ diameter $\mathrm{x} 0.5 \mathrm{~mm}$ height) were placed, coinciding with the areas demarcated by the tape, and filled with composite resin (Filtek Z350 XT, 3M ESPE, Sumaré, SP, Brazil), which was light-cured for 20 seconds.

After building three composite resin cylinders in each specimen, they were stored in distilled water $\left(37^{\circ} \mathrm{C}\right.$ for 24 hrs). Next, the Tygon ${ }^{\circledR}$ tubes were removed, and the specimens were loaded into a universal test machine (Kratos Equipamentos Ltda, Cotia, SP, Brazil) to perform the microshear test at a crosshead speed of $0.5 \mathrm{~mm} / \mathrm{min}$.

\section{Measurement of MMP activity}

The rectangular dentin fragments, as described above, represented approximately $40 \mathrm{~mm}^{2}$ of dentin, which has an equivalent area to a Class I cavity prepared in a mandibular first molar with $2 \mathrm{~mm}$ depth $\times 3 \mathrm{~mm}$ wide $\times 4$ mm length, ${ }^{16}$ being these dimensions clinically relevant. To evaluate the activity of MMPs, purified recombinant MMP-9 (AnaSpec Inc., cat\# 72,009, San Jose, CA, USA) and a generic MMP kit (SensoLyte Generic MMP colorimetric assay kit; cat\# 72,095, AnaSpec Inc., San Jose, CA, USA) were used. The assay involved the incubation of a constant concentration of rh MMP-9 with a proprietary chromogenic substrate. Thus, the kit measured the total activity of endogenous MMP, with the exception of MMP-20. The rh MMP-9 was used as a positive control, as an example representative of the maximum MMP activity present in dentin. ${ }^{17}$

After the treatments (Table 2), a 96-well plate was used for the allocation of dentin fragments containing $200 \mu \mathrm{L} /$ well of the generic MMP substrate, where incubation occurred for $60 \mathrm{~min}$. To avoid 96-well plate's light scattering during readings (a total of 6 readings), the dentin fragments were removed in a 10 min intervals, and the absorbance of the total endogenous activity was measured in a plate reader at 412 nm (Synergy HT, BioTek Instruments Inc., Winooski, VT, USA) against appropriate blanks. ${ }^{17}$

The rh MMP-9 was activated using trypsin to a final concentration of $10 \mu \mathrm{g} / \mathrm{ml}, \mathrm{pH} 7.4$ at $37^{\circ} \mathrm{C}$ for $2 \mathrm{hrs}$. The trypsin was inactivated by adding trypsin inhibitor to a final concentration of $100 \mu \mathrm{g} / \mathrm{ml}^{16}$

\section{Statistical analysis}

The microshear and MMP activity test data were subjected to the Shapiro-Wilk normality test, and one-way analysis of variance (ANOVA) was used to test the difference among groups, followed by Tukey's test for multiple comparisons $(p \leq 0.05)$.

\section{Results Microshear}

The microshear bond strength was affected by the different treatments $(p<0.0001)$. The mean and standard deviation for each group are shown in Table 1. Dental bleaching significantly reduced bond strength values when the adhesive strategy was performed at $24 \mathrm{hrs}(12.04 \mathrm{MPa})$, regardless of SA application. As well as 30 days after the end of treatment $(11.82 \mathrm{MPa})$. However, after 30 days, the prior application of SA on the bleached dentin substrate produced strength values (16.60 $\mathrm{MPa})$ that were statistically similar to those of the unbleached specimens (17.68 MPa).

\section{MMP activity}

The effect of different treatments on the MMP activity in dentin was significant $(p<0.0001)$. The mean and standard deviation of the MMP activity (absorbance) for each treatment are shown in Table 2. All the dentin treatments resulted in activation of the MMPs. The conditioning with 37\% phosphoric acid generated higher MMP activity ( 0.104 of absorbance) than the other treatments, with an exception when compared to G3 (acid etched and adhesive hybridized group). The use of $10 \%$ SA did not affect the 
MMP activity in groups G5 and G6, which was similar to that in the control group (G1).

\section{Discussion}

The results of the present study demonstrated that SA did not inhibit the activity of MMPs or re-establish the compromised bond strength in the bleached dentin immediately after the bleaching treatment. After 30 days, the bleaching treatment continued to negatively affect the bond strength. However, in specimens in which bleaching was followed by SA application, the bond strength significantly improved and was similar to that of unbleached samples. This finding may be related to the antioxidant effect of SA, added to the small amount of residual oxygen present in the bleached substrate after 30 days of storage. Thus, the null hypothesis tested was partially accepted.

Sodium ascorbate is a sodium salt of ascorbic acid with a neutral $\mathrm{pH}(\mathrm{pH}=7.4)$. Previous studies have suggested that sodium ascorbate is an antioxidant capable of reducing the amount of residual oxygen in the tooth structure and can be effective in the promotion of the bond strength of bleached dentin. ${ }^{8,18}$ The observed effects in the present study from some of the findings reported in the literature because of the wide variability of SA application protocols, combined with different concentrations and times of exposure to bleaching agents. ${ }^{3-6}$ However, a study that evaluated the kinetics of the reaction between SA and $35 \%$ hydrogen peroxide observed that a long period of exposure to SA does not affect the effectiveness of the reaction, with 5 mins being sufficient for SA to exert its antioxidant power. ${ }^{19}$ The short lifetime of SA is associated with variations in $\mathrm{pH}$ and temperature. ${ }^{20}$

The by-products generated during the degradation of the bleaching agents, in addition to compromising the infiltration and polymerization of the adhesive system, ${ }^{21}$ can cause oxidative stress to the pulp cells due to the imbalance between the production of reactive oxygen species and the presence of endogenous and exogenous antioxidants. ${ }^{22}$ Furthermore, these reactive species induce changes in the cellular membrane, allowing a marked increase in the free $\mathrm{Ca}^{2+}$ concentration, which can induce calcium-dependent catabolic processes such as the activation of phospholipases, endonucleases, and proteases. ${ }^{12}$

It is speculated that SA can interact with and stabilize reactive oxygen species (ROS), consequently preventing and/or minimizing oxidative damage to important biological structures such as DNA, proteins, and lipids. ${ }^{12}$ However, in the present study, the MMPs remained active in the bleached dentin even after SA application. The MMPs' activity of bleached and SA exposed group was similar to positive control (G1). The literature shows that the application of bleaching agents leads to denaturation of the dentin proteins by the oxidizing agents, ${ }^{23}$ and may cause a modification in the chemistry of the dental hard tissues, altering the ratio between organic and inorganic components. ${ }^{24}$ Besides, oxidants may also inactivate the tissue inhibitors of metalloproteases. ${ }^{11}$ In this sense, exposure of MMP-2 and -9 to a low $\mathrm{pH}$, followed by neutralization, has been shown to enhance the proteolytic activity of these enzymes. ${ }^{25}$ Thus, the $\mathrm{pH}$ neutralization caused by SA may create a favourable environment for the activity of these proteases.

In the present study, groups subjected to bleaching showed significant MMP activity similar to that of the control group, which is consistent with the literature demonstrating increased MMP activity in bleached dentin. ${ }^{11}$ Recently, it has been observed that bleaching agents also increase the activity of cysteine cathepsins in dentin, which function at both acidic and neutral $\mathrm{pH}$ and induce the activation of MMPs. ${ }^{13,26}$ Furthermore, oxidants can inactivate tissue inhibitors of MMPs. ${ }^{11}$

No significant difference in MMP activity in bleached dentin was observed with SA application and/or acid conditioning. However, in this study, the activity of MMPs was evaluated immediately after the end of the dentin treatments. It is likely that in long-term evaluations, the activity of MMPs will become even more evident since the degradation of collagen by these proteases is slow, resulting in a 36-70\% loss of bond strength after 12-14 months. ${ }^{16}$

Although all the performed treatments activated the dentin MMPs, the highest proteolytic activity observed occurred in the specimens exposed to $37 \%$ phosphoric acid conditioning only. Other studies have shown that $37 \% \mathrm{PA}$ causes the activation of MMPs and, for this reason, this treatment was designated as the second positive control. ${ }^{11,16}$ After this treatment of the dentin surface, the $\mathrm{pH}$ is considerably reduced, allowing these enzymes to be released from the mineral component, activated, and therefore able to degrade the exposed collagen. ${ }^{16}$

Some studies have suggested that hydrophilic monomers can encapsulate and mobilize the catalytic sites of MMPs, thus inhibiting collagen degradation. ${ }^{11,27}$ However, after infiltration of the Single Bond Universal adhesive, the MMP activity was similar to that of the specimens that were acid-conditioned only. After evaluating several adhesive systems in dentin subjected to total acid conditioning, 
Mazzoni and contributors observed that the endogenous MMP activity is adhesive-dependent, remaining active even after application of the bond system. ${ }^{28}$ These findings corroborate the results of the present study. Furthermore, the location of the proteolytic activity has been positively correlated with the demineralized and non-infiltrated collagen region within the hybrid layer. ${ }^{29}$

Factors such as concentration, exposure time to bleaching agents, and patient age may influence the deleterious effects caused by tooth bleaching. In the present study, teeth extracted from young patients were used. Thus, it should be taken into consideration that the levels of MMPs and cathepsins present in dentin decrease with age. ${ }^{26}$ It is also worth mentioning that in vital teeth, dentinal fluid flow is generated by intrapulpal pressure, which hinders the diffusion of bleaching gel components into the dentinal tubules. ${ }^{30}$ Additionally, the oxidative stress caused by free radicals activates the pulp cell defence system, releasing several endogenous antioxidants, such as peroxidases and catalases, which aid in the enzymatic degradation of $\mathrm{H}_{2} \mathrm{O}_{2}$ to avoid excessive tissue damage. ${ }^{30}$ Such characteristics, which were not reproduced in this in vitro study, can minimize the observed effects.

Although several studies have tested the effect of SA on bond strength, this is the first study to evaluate the effect of SA on the activity of MMPs in bleached dentin. In this context, it is premature to establish a relationship between bond strength and proteolytic activity in the substrate subjected to the bleaching treatment. Therefore, further studies should be conducted to improve our understanding of the effects of SA application on the previously bleached dental structure.

\section{Conclusion}

Sodium ascorbate (SA) has no inhibitory effect on collagenolytic activity of MMPs and on immediate bond strength ( $24 \mathrm{~h})$ of bleached dentin. When bonding procedures were delayed for 30 days, SA showed to be effective in recover bond strength values of previous bleached dentin.

\section{Acknowledgment}

The authors thank CAPES (Coordination for the Improvement of Higher Education Personnel) for the financial support.

\section{Disclosure}

The authors declare that they have no conflicts of interest in relation to this work.

\section{References}

1. Attin T, Hannig C, Wiegand A, Attin R. Effect of bleaching on restorative materials and restorations - a systematic review. Dent Mater. 2004;20(9):852-861.

2. Joiner A. The bleaching of teeth: a review of the literature. J Dent. 2006;34(7):412-419. doi:10.1016/j.jdent.2006.02.002

3. Kimyai S, Valizadeh H. The effect of hydrogel and solution of sodium ascorbate on bond strength in bleached enamel. Oper Dent. 2006;31(4):496-499. doi:10.2341/05-85

4. Kimyai S, Valizadeh H. Comparison of the effect of hydrogel and a solution of sodium ascorbate on dentin-composite bond strength after bleaching. J Contemp Dent Pract. 2008;9(2):105-112.

5. Tabatabaei MH, Arami S, Nojoumian A, Mirzaei M. Antioxidant effect on the shear bond strength of composite to bleached bovine dentin. Braz J Oral Sci. 2011;10(1):33-46.

6. Briso AL, Rahal V, Sundfeld RH, Dos Santos PH, Alexandre RS. Effect of sodium ascorbate on dentin bonding after two bleaching techniques. Oper Dent. 2014;39(2):195-203. doi:10.2341/12-054-L

7. Forner L, Salmerón-Sánchez M, Palomares M, Llena C, Amengual $\mathrm{J}$. The use of atomic force microscopy in determining the stiffness and adhesion force of human dentin after exposure to bleaching agents. $J$ Endod. 2009;35(10):1384-1396. doi:10.1016/j. joen.2009.05.031

8. Feiz A, Moslehb H, Nazeri R. Evaluating the effect of antioxidant agents on shear bond strength of toothcolored restorative materials after bleaching: a systematic review. J Mech Behav Biomed Mater. 2017;71:156-164. doi:10.1016/j.jmbbm.2017.03.010

9. Almahdy A, Koller G, Sauro S, et al. Effects of MMP inhibitors incorporated within dental adhesives. J Dent Res. 2012;91(6):605611. doi: $10.1177 / 0022034512446339$

10. Zheng P, Zaruba H, Attin T, Wiegand A. Effect of different matrix metalloproteinase inhibitors on microtensile bond strength of an etchand-rinse and a self-etching adhesive to dentin. Oper Dent. 2015;40 (1):80-86. doi:10.2341/13-162-L

11. Toledano M, Yamauti M, Osorio E, Osorio R. Bleaching agents increase metalloproteinases-mediated collagen degradation in dentin. J Endod. 2011;37(12):1668-1672. doi:10.1016/j.joen.2011.08.003

12. Lima AF, Lessa FC, Mancini MN, Hebling J, Costa CA, Marchi GM. Transdentinal protective role of sodium ascorbate against the cytophatic effects of $\mathrm{H} 2 \mathrm{O} 2$ released from bleaching agents. Oral Surg Oral Med Oral Pathol Oral Radiol Endod. 2010;109(4):70-76. doi:10.1016/j.tripleo.2009.12.020

13. Sato C, Rodrigues FA, Garcia DM, et al. Tooth bleaching increases dentinal protease activity. J Dent Res. 2013;92(2):187-192.

14. Dental materials - testing of adhesion to tooth structure. 2nd ed ed. Switzerland: Technical specification ISO/TS 11405;2003.

15. Aguiar JD, Medeiros IG, Souza Junior MH, Loretto SC. Influence of the extended use of desensitizing toothpastes on dentin bonding, microhardness and roughness. Braz Dent J. 2017;28(3):346-353. doi:10.1590/0103-6440201601292

16. Scheffel DL, Hebling J, Scheffel RH, et al. Inactivation of matrixbound matrix metalloproteinases by cross-linking agents in acidetched dentin. Oper Dent. 2013;38(2):152-158.

17. Tezvergil-Mutluay A, Agee KA, Hoshika T, et al. Inhibition of MMPs by alcohols. Dent Mater. 2011;9(2):926-933. doi:10.1016/j.dental. 2011.05.004

18. Perdigão J, Reis A, Loguercio AD. Dentin Adhesion and MMPs: a Comprehensive Review. $J$ Esthet Restor Dent. 2013;25(4):219-241. doi:10.1111/jerd.12016

19. Freire A, Souza EM, de Menezes Caldas DB, et al. Reaction kinetics of sodium ascorbate and dental bleaching gel. J Dent. 2009;37 (12):932-936. doi:10.1016/j.jdent.2009.05.007

20. Garcia EJ, Oldoni TL, Alencar SM, Reis A, Loguercio AD, Grande RH. Antioxidant activity by DPPH assay of potential solutions to be applied on bleached teeth. Braz Dent J. 2012;23(1):22-27. 
21. Souza-Gabriel AE, Vitussi LO, Milani C, Alfredo E, Messias DC, Silva-Sousa YT. Effect of bleaching protocols with $38 \%$ hydrogen peroxide and post-bleaching times on dentin bond strength. Braz Den J. 2011;22(4):317-321. doi:10.1590/S0103-6440201100040 f0010

22. Coldebella CR, Ribeiro AP, Sacono NT, Trindade FZ, Hebling J, Costa CA. Indirect cytotoxicity of a $35 \%$ hydrogen peroxide bleaching gel on cultured odontoblast-like cells. Braz Dent J. 2009;20 (4):267-274. doi:10.1590/S0103-64402009000400001

23. Ho S, Goerig AC. An in vitro comparison of different bleaching agents in the discoloured tooth. J Endod. 1989;15(3):106-111. doi:10.1016/S0099-2399(89)80129-3

24. Plotino G, Buono L, Grande NM, et al. Nonvital tooth bleaching: a review of the literature and clinical procedures. J Endod. 2008;34 (4):394-407. doi:10.1016/j.joen.2007.12.020

25. Carrilho MR. Can exogenous protease inhibitors control dentin matrix degradation? J Dent Res. 2012;91(12):1099-1102. doi:10.1177/0022034512462399
26. Tersariol IL, Geraldeli S, Minciotti CL, et al. Cysteine cathepsins in human dentin-pulp complex. $J$ Endod. 2010;36(3):475-481. doi:10.1016/j.joen.2009.12.034

27. Osorio R, Yamauti M, Osorio E, et al. Zinc reduces collagen degradation in demineralized human denitn explants. J Dent. 2011;39 (2):148-153. doi:10.1016/j.jdent.2010.11.005

28. Mazzoni A, Nascimento FD, Carrilho M, et al. MMP Activity in the hybrid layer detected with in situ zymography. J Dent Res. 2012;91 (5):467-472. doi:10.1177/0022034512439210

29. Mazzoni A, Apolonio FM, Saboia VP, et al. Carbodiimide inactivation of MMPs and effect on dentin bonding. J Dent Res. 2014;93 (3):263-268. doi:10.1177/0022034513516465

30. Costa CA, Riehl H, Kina JF, Sacono NT, Hebling J. Human pulp responses to in-office tooth bleaching. Oral Surg Oral Med Oral Pathol Oral Radiol Endod. 2010;109(4):59-64. doi:10.1016/j.tripleo.2009.12.002

\section{Publish your work in this journal}

Clinical, Cosmetic and Investigational Dentistry is an international, peer-reviewed, open access, online journal focusing on the latest clinical and experimental research in dentistry with specific emphasis on cosmetic interventions. Innovative developments in denta materials, techniques and devices that improve outcomes and patient satisfaction and preference will be highlighted. The manuscript management system is completely online and includes a very quick and fair peer-review system, which is all easy to use. Visit http://www.dovepress.com/testimonials.php to read real quotes from published authors. 